\title{
Idiopathic myelitis presenting as Brown-Séquard syndrome: two case reports and a review of the literature
}

\author{
Xi Peng ${ }^{1}$ (I) and Liang Wang ${ }^{2^{*}}$ (D)
}

\begin{abstract}
Background: Brown-Séquard syndrome often occurs in spinal cord injury, and few myelitis patients present with Brown-Séquard syndrome

Case presentation: A 33-year-old Han man was admitted with neck pain plus numbness in the right limbs for 2 days and weakness in the left limbs for 1 day. Examination was significant for left limbs with grade 4 muscle power, positive left Babinski sign, diminished vibration sensation in the left limbs and decreased pain below the right clavicle dermatome. The cerebrospinal fluid (CSF) cell count was $24 \times 10^{6} / \mathrm{L}$, and the protein count was $185 \mathrm{mg} / \mathrm{L}$. Cervical magnetic resonance imaging (MRI) indicated abnormal swelling signals in the medulla-cervical cord long segment and enhanced signals in the C2-3 region. In the second case, a 47-year-old Han woman was admitted with weakness in the right lower limb and numbness in the left lower limb for more than 20 days. Examination was significant for the right lower limb with grade 4 muscle power, left knee hyperreflexia, positive left Babinski sign, diminished vibration sensation in the right lower limb and decreased pain below the right T2 dermatome. Cervical MRI indicated hyperintense and enhanced signals in the C7-T2 region. In these two cases, CSF culture, oligoclonal band (OB) and aquaporin 4 (AQP4) antibody were negative. Brain MRI was normal. Their symptoms and MRI results improved after treatment with methylprednisolone.
\end{abstract}

Conclusions: Myelitis can present as Brown-Séquard syndrome, providing an extended reference in terms of the differential diagnosis for clinical physicians.

Keywords: Brown-Séquard syndrome, Myelitis, Differential diagnosis

\section{Background}

Brown-Séquard syndrome describes a lesion involving only one side of the spinal cord, which is characterized by ipsilateral impaired proprioception, vibratory sensation and motor function, and contralateral loss of pain and temperature sensation [1]. It mostly occurs in spinal cord injury, extramedullary spinal cord tumors and spinal hemorrhages, and sometimes it is caused by

${ }^{*}$ Correspondence: wang0128_0@163.com

2 Department of Neurology, The First Affiliated Hospital of Chongqing Medical University, Chongqing 400016, China

Full list of author information is available at the end of the article demyelinating diseases such as multiple sclerosis [1]. However, few myelitis patients present with BrownSéquard syndrome. We describe two cases of myelitis presenting as Brown-Séquard syndrome.

\section{Case presentation}

Case 1

A 33-year-old Han man was admitted with neck pain plus numbness in the right upper and lower limbs for 2 days. Two days earlier, the patient had a cold and presented with neck pain, especially when turning his neck. Numbness was present in the right upper and lower limbs and was progressive. One day earlier, the patient presented original author(s) and the source, provide a link to the Creative Commons licence, and indicate if changes were made. The images or other third party material in this article are included in the article's Creative Commons licence, unless indicated otherwise in a credit line to the material. If material is not included in the article's Creative Commons licence and your intended use is not permitted by statutory regulation or exceeds the permitted use, you will need to obtain permission directly from the copyright holder. To view a copy of this licence, visit http://creativecommons.org/licenses/by/4.0/. The Creative Commons Public Domain Dedication waiver (http://creativeco mmons.org/publicdomain/zero/1.0/) applies to the data made available in this article, unless otherwise stated in a credit line to the data. 
with weakness in the left upper and lower limbs, which did not negatively affect his daily movement. No fever, headache, visual impairment or defecation disorders were observed. No abnormality was observed in the past medical history. Physical examination revealed the following: Vital signs were stable. Cranial nerves were normal. Muscle power of the left upper and lower limbs was grade 4. Muscle tone was normal and reflexes were normal in all four limbs. Pain was decreased below the level of the right clavicle, and proprioception and vibration sensation in the left upper and lower limbs were diminished. The left Babinski sign was positive. The results of a routine blood test, hepatorenal function examination, electrolyte examination and antinuclear antibody spectrum were normal. The cancer spectrum was negative. Serum herpes, Cytomegalovirus (CMV) and EpsteinBarr virus (EBV) deoxyribonucleic acid (DNA) levels were negative. The lumbar puncture cerebrospinal fluid (CSF) cell count was $24 \times 10^{6} / \mathrm{L}$, and the protein count was $185 \mathrm{mg} / \mathrm{L}$. CSF smear and acid-fast staining were negative. CSF culture, oligoclonal band (OB) and aquaporin 4 (AQP4) antibody were negative. Visual evoked potential (VEP) indicated normality in the P100 incubation period. Brain magnetic resonance imaging (MRI) was normal. Cervical MRI indicated abnormal swelling signals in the medulla-cervical cord long segment and enhanced signals in the C2-3 region (Fig. 1a-d). Myelitis was considered, and neuromyelitis optica spectrum disorders (NMOSD) with negative AQP4 antibody was not excluded. The patient was administered methylprednisolone (1000 $\mathrm{mg}$ for 5 days) and then prednisone $(65 \mathrm{mg}$, orally, once a day, reduced by $10 \mathrm{mg}$ per week). On the third day after methylprednisolone pulse therapy was administered, the symptoms improved significantly, and they were completely resolved after 14 days. Cervical MRI was rechecked and indicated that the swelling had been significantly reduced and that the enhanced lesions in the C2-3 region had shrunk (Fig. 1e-h).

\section{Case 2}

A 47-year-old Han woman was admitted with weakness in the right lower limb and numbness in the left lower limb for more than 20 days. More than 20 days earlier, the patient presented with weakness in the right lower limb without cause. Half a day later, numbness was observed in the left lower limb accompanied by a cold sensation. No defecation disorders were observed. Lumbar MRI at an external hospital indicated protrusion of the intervertebral disk in the S3-4 and S4-5 regions. The patient did not improve after lumbar disease was treated and had aggravated weakness in the right lower limb and walking difficulties.
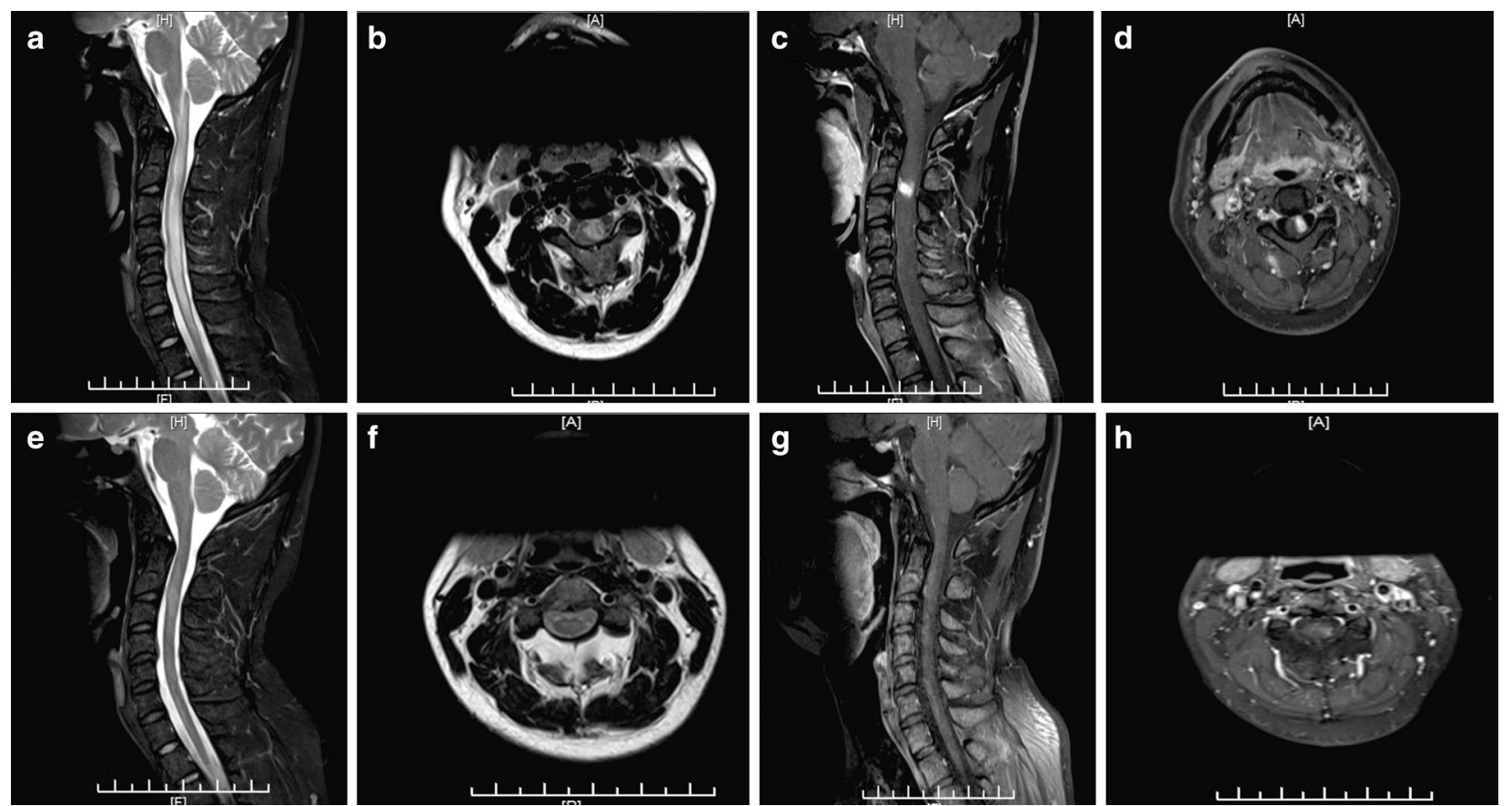

Fig. 1 a-d Cervical magnetic resonance imaging (MRI) shows hyperintense signal changes from the medulla to the cervical cord with long segments in the T2-weighted image and enhanced signals from C2 to C3 in the T1-weighted image: a midsagittal T2-weighted image, $\mathbf{b}$ axial T2-weighted image, c midsagittal contrast-enhanced T1-weighted image, $\mathbf{d}$ axial contrast-enhanced T1-weighted image. $\mathbf{e}-\mathbf{h}$ After treatment, cervical MRI shows that the swelling was reduced and that there were fewer enhanced lesions in the C2-3 region 
No abnormalities were observed in the past medical history. Physical examination: Vital signs were stable. Cranial nerves were normal. Grade 4 muscle power was found in the right lower limb, while grade 5 muscle power was revealed in the left lower limb. Normal muscle tone was found in all four limbs. The knee reflex was exaggerated in her right lower limb. Pain was reduced below the left sternal angle. Proprioception and vibration sensation in the right lower limb were diminished. The right Babinski sign was positive. The results of a routine blood test, hepatorenal function examination, electrolyte examination and antinuclear antibody spectrum were normal. Serum herpes, CMV and EBV DNA levels were negative. The CSF cell count was $1 \times 10^{6} / \mathrm{L}$, and the protein level was $328 \mathrm{mg} / \mathrm{L}$. CSF smear and acid-fast staining were negative. CSF culture, $\mathrm{OB}$ and AQP4 antibody were negative. Brain MRI was normal. Cervical MRI indicated hyperintense and enhanced signals in the C7-T2 region (Fig. 2a-d). Myelitis was considered. The patient was administered methylprednisolone (1000 $\mathrm{mg}$ for 5 days) and then prednisone $(55 \mathrm{mg}$, orally, once a day, reduced by $10 \mathrm{~g}$ per week). After methylprednisolone pulse therapy was given, the symptoms were significantly improved. Fifteen days later, cervical MRI was rechecked, indicating that the lesions were significantly reduced (Fig. 2e-h). The patient recovered and was discharged.

\section{Discussion and conclusion}

These two cases had no obvious causes and were considered idiopathic myelitis. Acute myelitis is a clinically transverse injury of the spinal cord, with symmetric limb weakness, symmetric sensory disturbances below the damaged segment and defecation disorders. However, few myelitis patients present with Brown-Séquard syndrome. A total of 22 studies were found on PubMed with the search term "Brown-Séquard syndrome and myelitis," of which nine studies indicated myelitis presenting as Brown-Séquard syndrome, as shown in our case report. Among the nine patients (male/female $=6: 3$ ) aged 13-53 years, the cause in four was diagnosed as viral infection, two as post-viral vaccination, two as idiopathic disease, and one as bacterial infection; five patients presented with the greatest damage in the thoracic segments and three in the cervical segments; one case was MRI-negative (Table 1).

Case 1 presented as a long damaged segment with negative AQP4 antibody and was considered as NMOSD with negative AQP4 antibody. In accordance with the diagnostic criteria for NMOSD with negative AQP4 antibody, the patient presented with only one core clinical symptom of NMOSD. The patient also
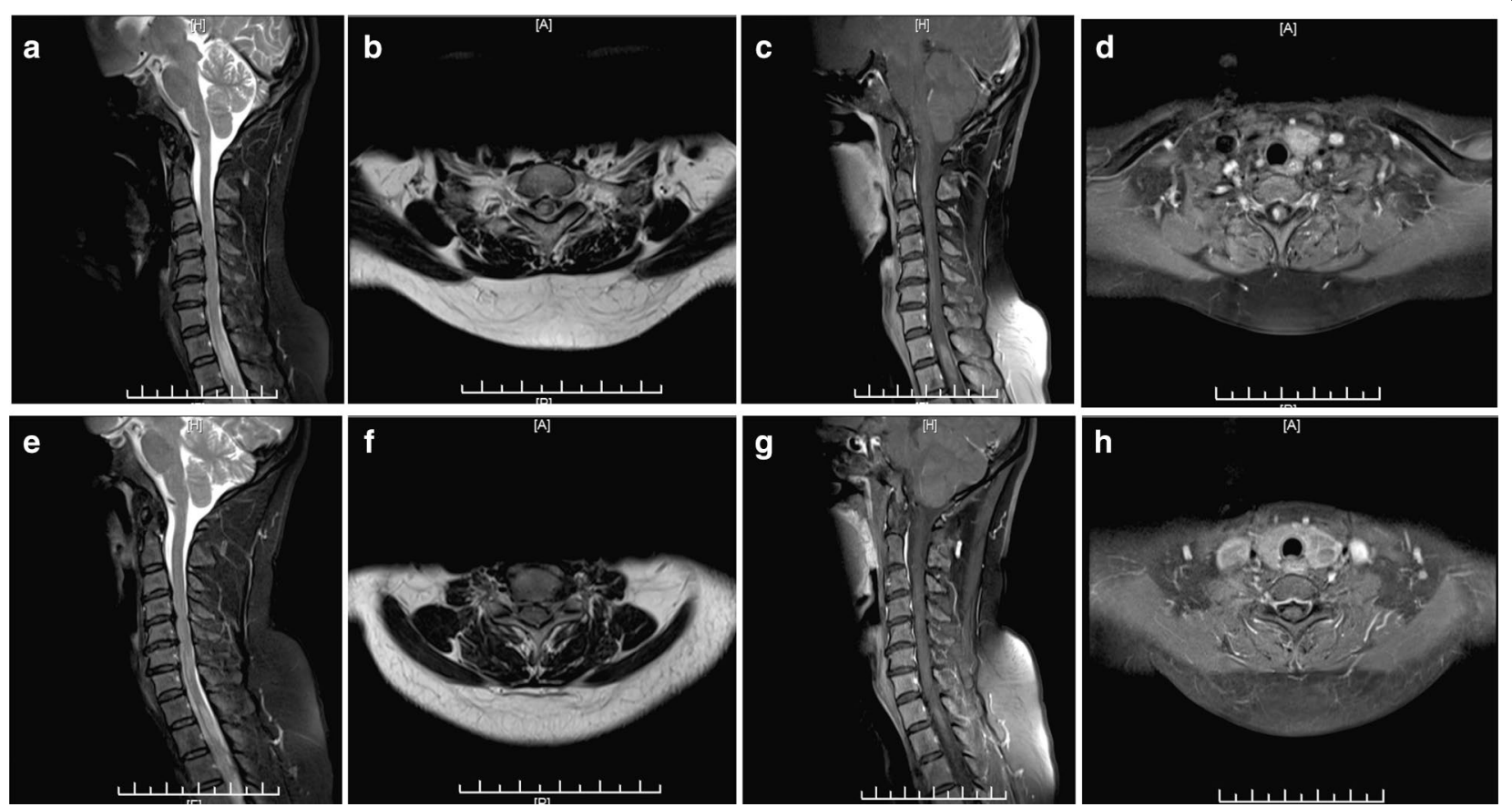

Fig. 2 a-d Cervical magnetic resonance imaging (MRI) shows hyperintense signal changes from C7 to T2 in the T2-weighted image and shows the gadolinium-enhanced lesion in the T1-weighted image. $\mathbf{e}-\mathbf{h}$ After treatment, cervical MRI shows that the swelling was reduced and that there were fewer enhanced lesions in the C7-T2 region 
Table 1 Information on the published case reports with "BrownSéquard syndrome and myelitis"

\begin{tabular}{|c|c|c|c|c|}
\hline Cases & Sex & $\begin{array}{l}\text { Age } \\
\text { (years) }\end{array}$ & Cause & Location \\
\hline $\begin{array}{l}\text { Abdul-Ghaffar } \\
1988 \text { [3] }\end{array}$ & Male & 48 & Virus & C5 \\
\hline $\begin{array}{l}\text { Abdul-Ghaffar } \\
1994 \text { [4] }\end{array}$ & Male & 13 & $\begin{array}{l}\text { Diphtheria and } \\
\text { tetanus vaccina- } \\
\text { tions }\end{array}$ & C4 \\
\hline Titlic 2006 [5] & Female & 20 & $\begin{array}{l}\text { Meningococcal } \\
\text { sepsis }\end{array}$ & $\mathrm{T}$ \\
\hline Moon 2009 [6] & Male & 38 & Idiopathic & $\mathrm{T} 11$ \\
\hline Hosaka 2010 [7] & Female & 32 & Herpes zoster & $\mathrm{T} 3-4$ \\
\hline Vieira 2012 [8] & Female & 52 & $\begin{array}{l}\text { H1N1 immuniza- } \\
\text { tion }\end{array}$ & $\mathrm{T}$ \\
\hline Dubey 2014 [9] & Male & 53 & CMV and AIDS & T5 \\
\hline $\begin{array}{l}\text { Yamamoto } 2019 \\
\text { [10] }\end{array}$ & Male & 47 & Idiopathic & C3-4 \\
\hline Elsayed 2019 [11] & Male & 46 & Varicella zoster & MRI (-) \\
\hline
\end{tabular}

CMV Cytomegalovirus, AIDS acquired immunodeficiency syndrome, MRI magnetic resonance imaging, $C$ cervical, $T$ thoracic

lacked other common symptoms of NMOSD, such as optic neuritis, posterior polar syndrome and brainstem syndrome [2]. If the patient had presented with other clinical symptoms or relapse, we could have diagnosed NMOSD. The onset in case 2 was typical of BrownSéquard syndrome. However, the patient presented with weakness of both lower limbs, and MRI images only indicated lesions on the right side, indicating that the swelling caused by the lesions involved the left side or that the left lesion involved the left pyramidal tract, but this was not shown on MRI.

Brown-Séquard syndrome is caused by traumatic factors and nontraumatic factors. Traumatic factors are more common, for example, traffic accident injuries and blunt injuries, while nontraumatic factors include disk herniation, cervical spondylosis, tumors, multiple sclerosis, radioactive damage, decompression disease and spinal cord ischemia or bleeding. Infections also represent a nontraumatic factor, for example, tuberculosis, viruses including herpes zoster, bacterial infections and idiopathic transverse myelitis caused by infection-induced immune responses [1].

This case report demonstrates that myelitis can present as Brown-Séquard syndrome, providing an extended reference in terms of the differential diagnosis for clinical physicians.

\section{Abbreviations}

CSF: Cerebrospinal fluid; MRI: Magnetic resonance imaging; OB: Oligoclonal band; AQP4: Aquaporin 4; CMV: Cytomegalovirus; EBV: Epstein-Barr virus; VEP: Visual evoked potential; NMOSD: Neuromyelitis optica spectrum disorders.

\section{Acknowledgements}

Not applicable.

\section{Authors' contributions}

XP and LW had access to all the data in the study, read and approved the submission, and contributed to the idea, data collection and manuscript preparation. Both authors read and approved the final manuscript.

\section{Funding}

This study was supported by the Joint Medical Research Project of Chongqing Science \& Technology and Health Commission [number 2020FYYX081] and the grant of Outstanding Youth of Kuan Ren in the Second Affiliated Hospital of Chongqing Medical University.

\section{Availability of data and materials \\ Not applicable.}

\section{Declarations}

Ethics approval and consent to participate

This study was approved by the Ethical Review Committee of the First Affiliated Hospital of Chongqing Medical University (Chongqing, China). The patient approved participation in this study.

\section{Consent for publication}

Written informed consent was obtained from the patients for publication of this case report and any accompanying images. A copy of the written consent is available for review by the Editor-in-Chief of this journal.

\section{Competing interests}

The authors declare that they have no competing interests.

\section{Author details}

${ }^{1}$ Department of Neurology, The Second Affiliated Hospital of Chongqing Medical University, Chongqing 400010, China. ${ }^{2}$ Department of Neurology, The First Affiliated Hospital of Chongqing Medical University, Chongqing 400016, China.

Received: 27 January 2020 Accepted: 29 March 2021

Published online: 12 May 2021

\section{References}

1. Shams S, Arain A. Brown Sequard Syndrome. Treasure Island: StatPearls; 2019.

2. Wingerchuk DM, Banwell B, Bennett JL, Cabre P, Carroll W, Chitnis T, de Seze J, Fujihara K, Greenberg B, Jacob A, et al. International consensus diagnostic criteria for neuromyelitis optica spectrum disorders. Neurology. 2015;85(2):177-89

3. Berlit P. Rare causes of the Brown-Sequard syndrome. NMR tomographic findings. Dtsch Med Wochenschr. 1988;113(47):1844-6.

4. Abdul-Ghaffar NU, Achar KN. Brown-Sequard syndrome following diphtheria and tetanus vaccines. Trop Doct. 1994;24(2):74-5.

5. Titlic M, Milas I, Tonkic A, Jukic I, Kolic K. Diagnostics of incomplete Brown-Sequard syndrome caused by meningococcal myelitis. Bratisl Lek Listy. 2006;107(8):287-9.

6. Moon SJ, Lee JK, Kim TW, Kim SH. Idiopathic transverse myelitis presenting as the Brown-Sequard syndrome. Spinal Cord. 2009;47(2):176-8.

7. Hosaka A, Nakamagoe K, Watanabe M, Tamaoka A. Magnetic resonance images of herpes zoster myelitis presenting with Brown-Sequard syndrome. Arch Neurol. 2010;67(4):506. 
8. Vieira MA, Costa CH, Vieira CP, Cavalcanti Mdo A, Ferreira-Filho SP. Transverse myelitis with Brown-Sequard syndrome after H1N1 immunization. Arq Neuropsiquiatr. 2012;70(7):555.

9. Dubey D, Modur PN. Teaching Neurolmages: partial brownSequard syndrome: a rare presentation of CMV myelitis. Neurology. 2014;83(6):e80

10. Elsayed MAM, Aladil O, Elsadig SM, Ahmed MH, Noori SI. Challenging neurological presentations of varicella virus infections in Sudan: Clinical features, imaging and recommendations. J Family Med Prim Care. 2019;8(6):2161-4.
11. Yamamoto M, Satoi H, Matsumoto S. Acute myelitis with BrownSequard syndrome complicated with subjective sudomotor laterality and ileocecal abscess without right abdominal pain. Rinsho Shinkeigaku. 2019;59(5):282-5.

\section{Publisher's Note}

Springer Nature remains neutral with regard to jurisdictional claims in published maps and institutional affiliations.
Ready to submit your research? Choose BMC and benefit from:

- fast, convenient online submission

- thorough peer review by experienced researchers in your field

- rapid publication on acceptance

- support for research data, including large and complex data types

- gold Open Access which fosters wider collaboration and increased citations

- maximum visibility for your research: over $100 \mathrm{M}$ website views per year

At BMC, research is always in progress.

Learn more biomedcentral.com/submissions 